\title{
A Scheme of Dynamic Voltage Restorer to Improve Power Quality in Large Scale Industrial Enterprises
}

\author{
Shan Shi' ${ }^{1}$ Jun Xiao ${ }^{2}$, Shu Liu ${ }^{1}$, Liming Tu${ }^{1}$, Qin Cao ${ }^{1}$, Yu Liang ${ }^{2}$, Gaoyan Zhang², \\ Chengxiong $\mathrm{Mao}^{2}$ \\ ${ }^{1}$ Beijing Sifang Automation Co., Ltd., Beijing 100085, China \\ ${ }^{2}$ School of Electrical and Electronic Engineering, Huazhong University of Science and Technology, Wuhan \\ 430074, China \\ Email: xiaojun9283@163.com
}

Received 9 November 2015; accepted 15 February 2016; published 18 February 2016

\begin{abstract}
Loads in large scale industrial enterprises are always various and complex, causing insecure power quality. Meanwhile, some sensitive loads or precise instruments demand for high power quality. When voltage flicker or harmonics occurs, dynamic voltage restorer (DVR) can be used to stabilize the load-side voltage, which is a good manner of improving power quality. The paper explains the load demand in large scale industrial enterprises, analyzes several common voltage compensation scheme of DVR, and comes up with another voltage compensation scheme of DVR applied for double power supply with double load. A Simulink model according to the new scheme is also built in MATLAB/Simulink to test its performance. Simulation results show that the proposed scheme can guarantee the load-side voltage stability, which is an effective scheme for managing power quality.
\end{abstract}

\section{Keywords}

Power Quality, Large Scale Enterprises, Double Power Supply with Double Load, DVR Compensation Scheme

\section{Introduction}

Large scale industrial enterprises, electricity consumption of which accounts for $85 \%$ of total consumption in the whole country, are a major part of power distribution system (HUANG. 2011) [1] and demand for harsher power quality than normal users (Daniel, J. Love. 1994) [2]. In all kinds of power quality matter, voltage flicker occurs frequently and seriously impacts the normal work of load.

Dynamic voltage restorer (DVR) is a kind of controlled voltage source device, which is able to compensate the power needed. It has high efficiency, and costs less than other devices such as uninterruptible power supply, constant voltage transformer and motor-generator. Besides the basic voltage compensation function, DVR also can achieve the harmonics compensation and reactive power compensation function. It is the most effective and 
popular power electronic equipment solving the problem of voltage (HAN et al., 2003) [3]. Therefore, DVR can not only improve power supply reliability, but also enhance load-side power quality.

At present, there are three types of mostly studied DVR (Nielsen, G.J. \& Blaabjerg, F., 2005) [4]. DVR with DC capacitor is supposed to compensate reactive power only, otherwise, its DC voltage will decrease seriously as active power consuming. This method doesn't perform well in voltage compensation time and degree (Jothibasu, S. \& Mishra, K. M. 2014) [5]. DVR with energy storage system often chooses storage battery, superconducting magnetic energy storage or flywheel energy storage as energy source (Ramachandaramurthy, V.K. et al. 2002) (LIU. et al. 2004) (de Andrade R. et al. 2005) [6]-[8]. By this means, DVR is able to compensate reactive power as well as active power. However, it exits some problems using no matter which storage system, for example, cost will increase and control will be more complex. In DVR with rectifying system, in order to complete long-time compensation, DC capacitor is link to power supply side or load side through rectifying circuit. When voltage fault occurs in supply side, it is so difficult to maintain a constant DC voltage in DC part, and chances are that harmonics voltage or overvoltage will be introduced to DVR. Besides, rectifying circuit cannot obtain energy through power grid if grid voltage drops seriously, and chances are that more serious voltage drop will occur (YANG et al., 2004.) (YIN \& ZHI, 2005) [9] [10].

This paper comes up with a new voltage compensation scheme of DVR applied for double power supply with double load, which has the merits of both DVR with energy storage system and DVR with rectifying system. Simulink model of common scheme and model according to the new scheme are all built in MATLAB/Simulink, so that we could compare the merits or demerits between them. Simulation results show that the proposed scheme can guarantee the load-side voltage stability, which is an effective scheme for managing power quality.

\section{The Requirement of Power Quality in Large Scale Industrial Enterprises}

With the continuous development of science and technology, contradictions between sensitive loads and power quality polluting equipment in large scale industrial enterprises become more and more prominent. On the one hand, there are often a large number of imported equipment and precision instruments in large scale industrial enterprises, which demand high on power supply reliability and power quality (HUANG, 2012) [11]. If grid voltage is not stable, such as frequency fluctuates, waveform changes or short time power outages, it is likely to have a great impact on the production process and product quality. For example, some devices with sensitive relay protection maybe automatically jump to open, making the whole line in outage and resulting in huge economic losses. In recent years, voltage rising and dropping drastically or shot time power outages have become the most prominent problem, which influence the safe operation of the load in large scale industrial enterprises. If the problem is not serious, it maybe only make production line stop and production scrap; if the problem is serious, it will even cause production accident or human casualty (GUAN, 2012) [12]. On the other hand, the loads in large scale industrial enterprises always have outstanding characteristics such as nonlinear, impact or intermittent, and the start or stop of a single load will has much influence on power grid (FU \& WEI, 2011) [13]. Taking the iron and steel enterprises as an example, electric arc furnace is a typical nonlinear load, while rotating mill is a typical impact load, and both of them have a single capacity of MW level (SUN \& QIN, 2008) [14]. Electric arc furnace is a three-phase asymmetric load in melting period, while active and reactive power random change, which can cause voltage flicker fluctuations and negative sequence current and harmonic, etc. When rotating mill is in biting course, motor current is very big, but the active power is less than the rated active power, while the reactive power is much more than the rated reactive power. At this time, the rotating mill has the worst hit reactive power and lowest power factor to power grid.

In general, in all kinds of power quality problems, the occurred frequency of voltage flicker is the highest and its influence is the most serious. At present in industrialized countries, voltage flicker has increased to one of the most important power quality problems. According to reports, voltage flicker accounts for over $80 \%$ of all the complaints from customs about power quality problems, while voltage harmonics accounts for only less than $20 \%$ (YUAN, 2005) [15]. The effect of voltage flicker is so great because many industrial processes in large scale industrial enterprises are sensitive to it. These industrial processes involve many fields including semiconductor, papermaking, plastic, petrochemical, textile, glass and rubber, etc. Economic losses caused by voltage flicker include not only losses of product quality and production line stoppage, but also the costs on the whole production line start. According to reports, as a result of the four cycle of voltage drop, an enterprises takes 72 minutes to restore production line of work, causing a loss of 700 thousand dollars. Therefore, how to improve power supply reliability and power quality in large scale industrial enterprises is a problem to be solved. 


\section{Scheme of DVR Applied for Double Power Supply with Double Load}

DVR, which has very high performance value ratio, is a controlled voltage source device used to solve power quality problems such as voltage flicker and harmonics. It is set between load and power supply (Figure 1) to compensate the load side voltage when the power failure occurs or power supply side has temporarily voltage flicker or harmonics.

In large scale industrial enterprises, power supply adopts double standby power supply system, such as uninterruptible power supply, emergency power supply, bus-bar automatic transfer switch, system for the static switch and automatically transfer switch, against critical load. Two way power supply are spare to each other through the DVR scheme applied for double power supply with double load. If one way power supply failure or voltage drop occurs, DVR can obtain power from the other way. Compensation voltage is generated by the PWM inverter, and coupled to the circuit through the transformer.

Large scale industrial enterprises often appear three-phase asymmetric loads, single-phase inverter has been adopted so that three phase can be controlled independently. In this model, three phase are in equal status, therefore, we just need to analyze one phase, for example, phase A, and the other two phase is similar. In order to make the paper simpler, only one-phase structure will be analyzed in the latter part of this paper. The location of DVR (phase A) is shown as Figure 2.

Although the voltage flicker or harmonics occurs frequently in large scale industrial enterprises, the likelihood that two way power supply fail at the same time is much lower than just one way power supply. When source $S_{1}$ has voltage drop, source $S_{2}$ can still provide normal power supply. The single-phase inverter in the way of $S_{1}$ obtains the power from source $S_{2}$ to compensate voltage, so that the load side voltage of $\operatorname{LD}_{1}$ can maintain constant.

This scheme doesn't need any more storage device, and is able to solve the problem of the DVR with rectifying system: when voltage drops deeply, it can't compensate the voltage very well. Besides, there are always several power supply with several load in the large scale industrial enterprises, the scheme can be generalized in the situation of several power supply with several load. For example, if there are $m$ way power supply with $m$ way load, when source $S_{1}$ has voltage drop, the other $m-1$ way power supply will provide energy for the single-phase inverter in the way of $S_{1}$, in order to make the voltage stable in the way of $S_{1}$.

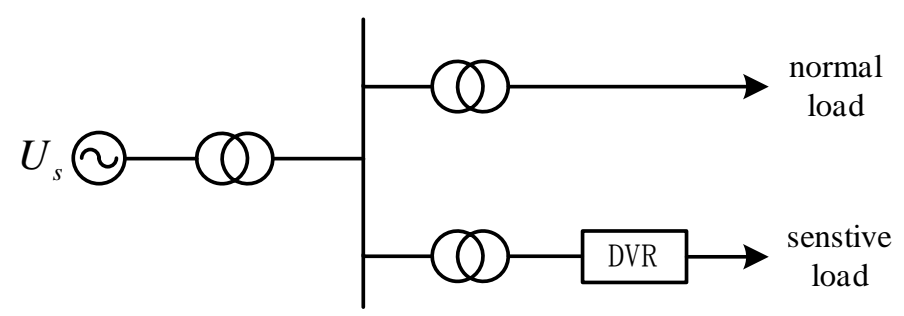

Figure 1. DVR installation location in the circuit.

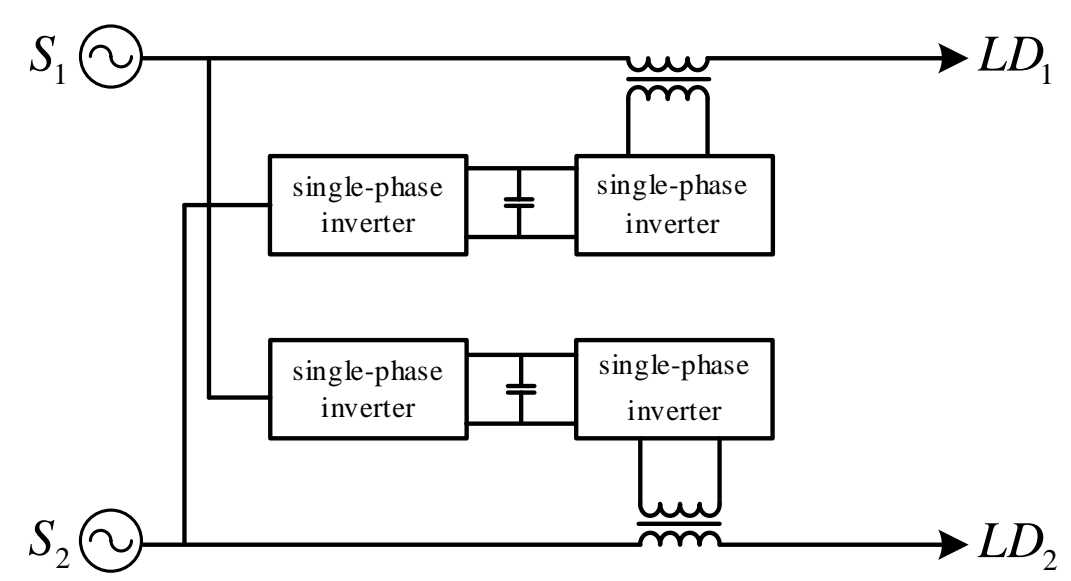

Figure 2. Scheme of DVR applied for double power supply with double load. 


\section{The Topological Structure and Unit Design of DVR}

\subsection{Design of Inverter Unit}

As mentioned earlier, large scale industrial enterprises often appear three-phase asymmetric loads. In three single-phase DVR with full-bridge configuration, each phase is independent of each other. Although a greater number of switching devices have been used and the cost increases as well, sub-phase control can be achieved and zero sequence voltage can be compensated in this way. In this way, DVR is more flexible and suitable for the extensive use of three-phase grid with a four-wire system structure in large scale industrial enterprises. The structure of single-phase inverter is shown in Figure 3.

The state space model of the structure is:

$$
\left\{\begin{array}{l}
L_{f} \frac{d i_{L}}{d t}+R_{f} i_{L}=S u_{d c}-v_{c} \\
C_{f} \frac{d v_{c}}{d t}=i_{L}-i_{c}
\end{array}\right.
$$

where $S$ = switching function.

Inverter has a variety of control and modeling methods, control core is the on-off control of four IGBT in single-phase H-bridge circuit (Wang, B. et al. 2006) [16]. Considering the voltage and current double loop control has good static and dynamic response performance, and is able to satisfy the need of DVR's rapidly response to the control system, double closed-loop control scheme based on the DVR output voltage and output filtering inductance current have been adopted, as shown in Figure 4.

The Figure 4 shows that the DVR voltage instruction signal $v_{c-r e f}$ is compared with actual offset voltage $v_{c}$, the difference of them is the error voltage signal, which produces the inductance current instruction signal $i_{L-r e f}$ through a PI regulator. The inductance current instruction signal $i_{L \text {-ref }}$ is compared with inductance current feedback signal $i_{L}$, the error signal between them produces the on-off signal $S$ through another PI regulator. In this double closed-loop control scheme, the current inner loop adopts a PI current regulator. The proportion cycle of current regulator is used to increase the damping coefficient of the inverter, make the whole system work steadily, and ensure the strong robustness, while the integral cycle is used to reduce the steady-state error of current loop. The voltage outer loop adopts a PI voltage regulator as well, which is used to make the instantaneous output voltage waveform track to a given value.

As a disturbance signal of inverter, the DVR compensating current $i_{c}$ is out of the current loop, so the control performance of the system for load disturbance is poor. In order to eliminate the load disturbance, the compensation current $i_{c}$ and voltage $v_{c}$ are introduced as feed forward control signal, reducing the PI mediator's mediation extent and the influence of external disturbance on the system control performance.

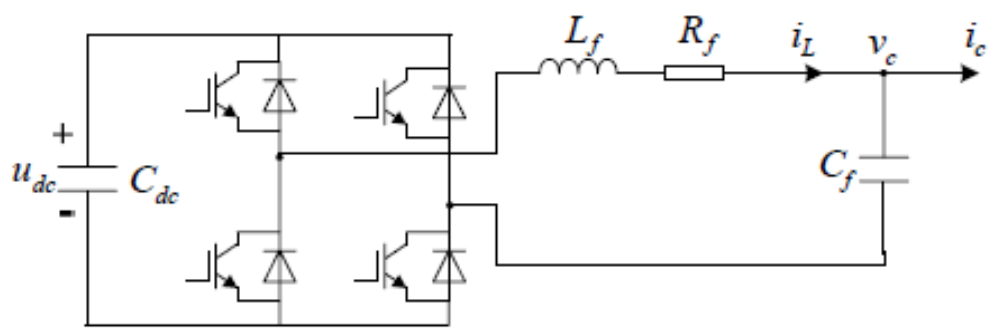

Figure 3. Structure of single-phase inverter.

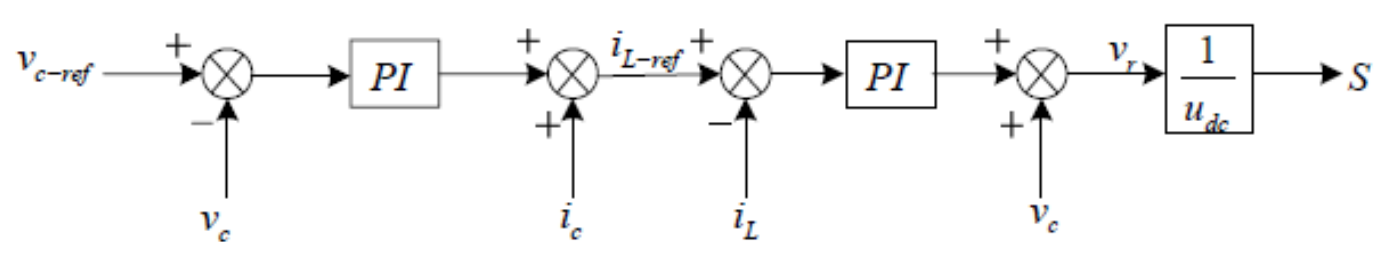

Figure 4. Double closed-loop control scheme. 


\subsection{Design of Detection Unit}

The detection unit is supposed to accurately and rapidly detect the voltage flicker amplitude, dropping start-stop time, phase jump angle and other relevant parameters. Generally, the d-q transformation method based on instantaneous voltage is common to use: the instantaneous voltage of positive sequence component is transferred to the DC component of d-q coordinate system, while negative sequence component is transferred to the double frequency component. After filtering processing, only positive sequence component is left.

In the single-phase system, d-q transformation can't be directly applied. Two-phase static coordinate system is supposed to be built according to single-phase voltage, then transferring it to the two-phase rotating coordinate system. It will have a large delay when built by 90-degrees-lag method, and will have an overshoot when built by derivative method. Small angle method can coordinate the contradiction between delay and overshoot. The method is constructed as follows.

Take the single-phase voltage as $\beta$-axis voltage, and obtain the $\alpha$-axis voltage by the expression

$$
\left\{\begin{array}{l}
U_{\beta}=U \sin (\omega t+\varphi) \\
U_{\beta}{ }^{\prime}=U \sin (\omega t+\varphi-\theta)
\end{array}\right.
$$

Then,

$$
U_{\alpha}=U \cos (\omega t+\varphi)=U_{\beta} / \tan \theta-U_{\beta}^{\prime} / \sin \theta
$$

According to the transformation formula:

$$
\left[\begin{array}{l}
U_{d} \\
U_{q}
\end{array}\right]=\left[\begin{array}{cc}
\cos \omega t & \sin \omega t \\
-\sin \omega t & \cos \omega t
\end{array}\right]\left[\begin{array}{l}
U_{\alpha} \\
U_{\beta}
\end{array}\right]
$$

where $U_{d}=$ single-phase instantaneous voltage amplitude.

\section{Rectifier DVR Simulation Results}

DVR with rectifying system obtains power from power supply side or load side, but many problems will occur when voltage drops seriously, even deteriorating power quality. The system parameters of simulation are shown in Table 1.

The simulation system is shown in Figure 5.

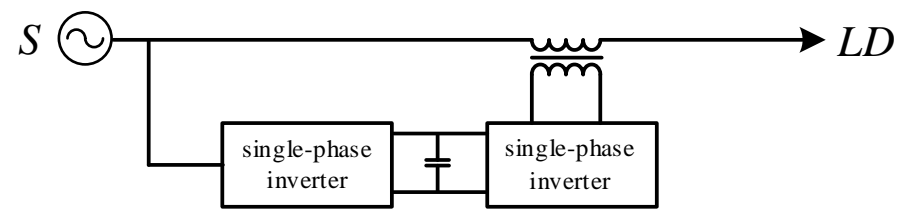

Figure 5. DVR with rectifying system.

Table 1. System parameters of simulation in rectifier DVR.

\begin{tabular}{cc}
\hline Parameters & Value \\
\hline Source voltage $\mathrm{V}_{\mathrm{s}}$ & $220 \mathrm{~V}$ \\
Load R & $1 \Omega$ \\
One-phase load capacity S & $4.84 \mathrm{kVA}$ \\
Transformer ratio K & 1 \\
DC voltage $\mathrm{V}_{\mathrm{dc}}$ & $400 \mathrm{~V}$ \\
Filtering inductance L & $4 \mathrm{mH}$ \\
Filtering capacitor C & $60 \mu \mathrm{F}$
\end{tabular}


In order to verify that the DVR with rectifying system may not work properly when the magnitude of the voltage drops seriously, the paper selects two conditions to simulate, one is the voltage drop to $30 \%$ of the rated values, another is $70 \%$ of the rated values. The simulation results are shown in Figure 6.

According to the simulation results, when amplitude of voltage drop is smaller, the DVR can be used to compensate the voltage drop, and load side voltage can be stabilize to the rated value. But when amplitude of voltage drops seriously, due to the DC side of DVR obtains energy from the supply side, DC voltage will decline, the DVR cannot fully compensate for voltage drop, which causes voltage distortion.

\section{Double Power Supply with Double Load Compensation Scheme Simulation Results}

When the double power obtain energy from each other, the possibility that two power supplies fail to work at the same time is much lower than that just one power supply is unable to work. The system parameters of simulation are shown in Table 2.

The simulation system is shown in Figure 2. In this simulation, the voltage amplitude of source $S_{1}$ drops to 30\% of the rated values, while another source $S_{2}$ works normally, the results of simulation are shown in Figure 7.

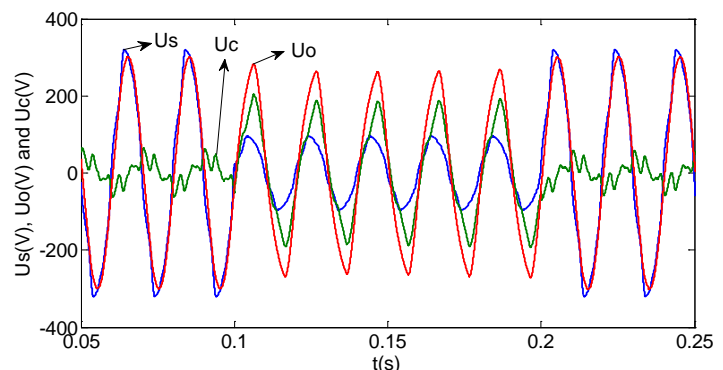

(a)

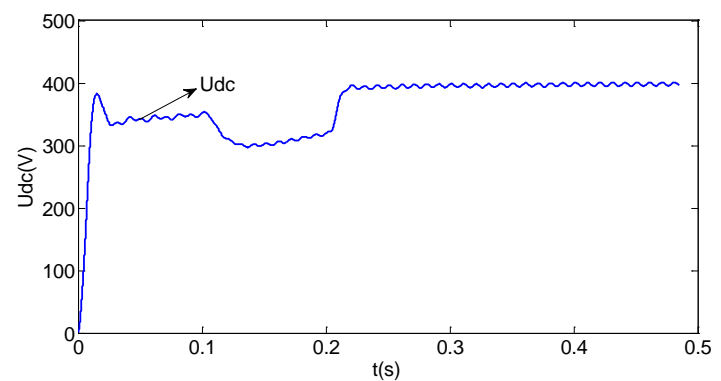

(c)

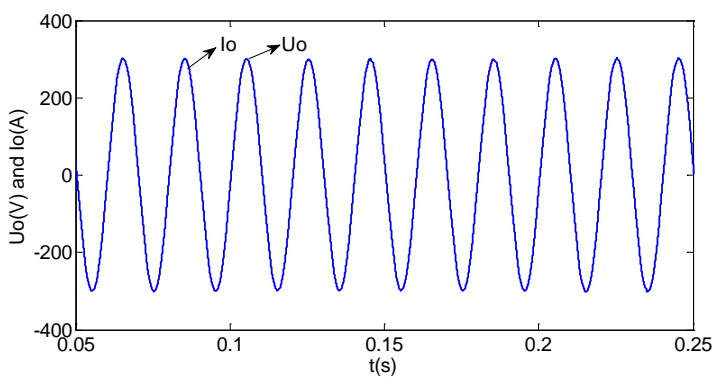

(e)

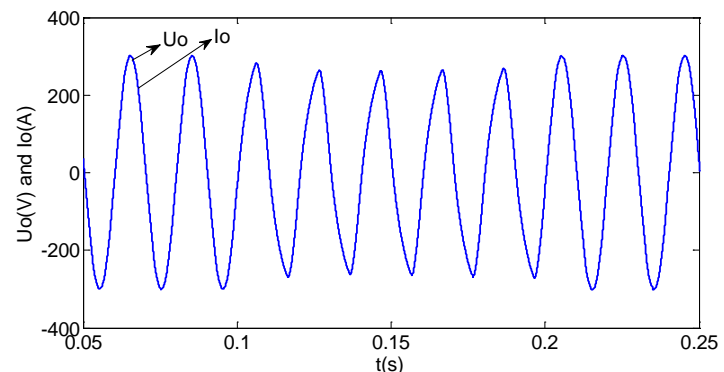

(b)

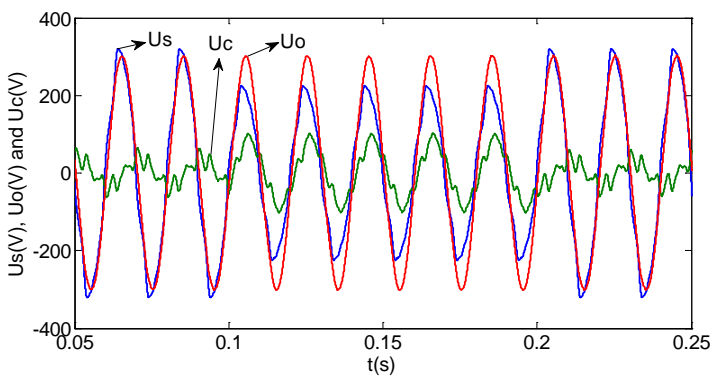

(d)

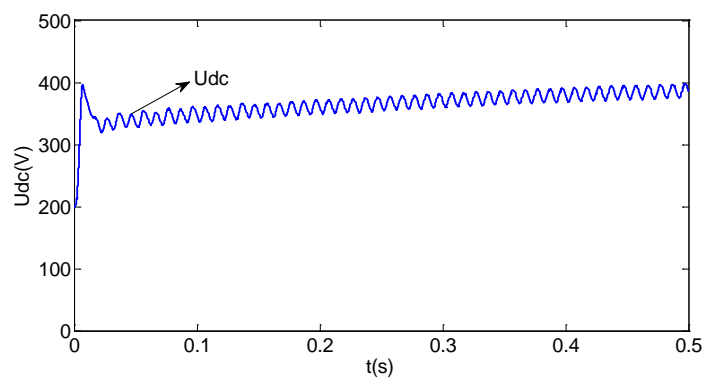

(f)

Figure 6. Simulation results. (a) Power voltage, load voltage and compensation voltage waveforms when the voltage drop to $30 \%$ of the rated values; (b) voltage and current waveforms in load side when the voltage drop to $30 \%$ of the rated values; (c) voltage waveform in DC side of DVR when the voltage drop to $30 \%$ of the rated values; (d) power voltage, load voltage and compensation voltage waveforms when the voltage drop to $70 \%$ of the rated values; (e) voltage and current waveforms in load side when the voltage drop to $70 \%$ of the rated values; (f) voltage waveform in DC side of DVR when the voltage drop to $70 \%$ of the rated values. 


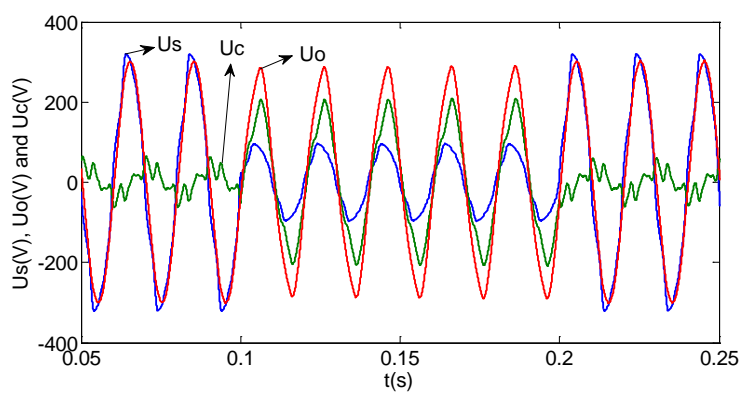

(a)

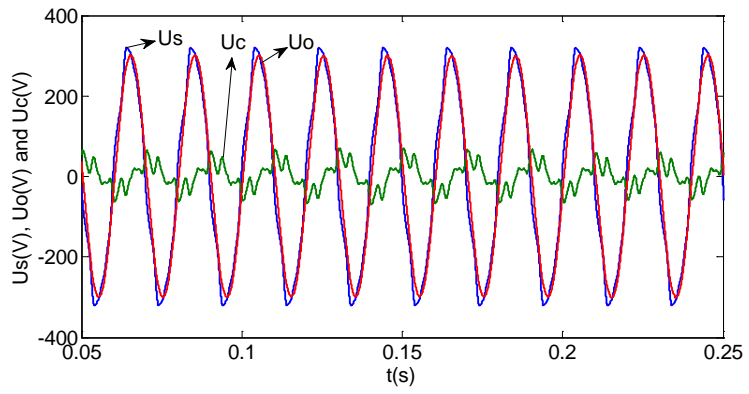

(c)

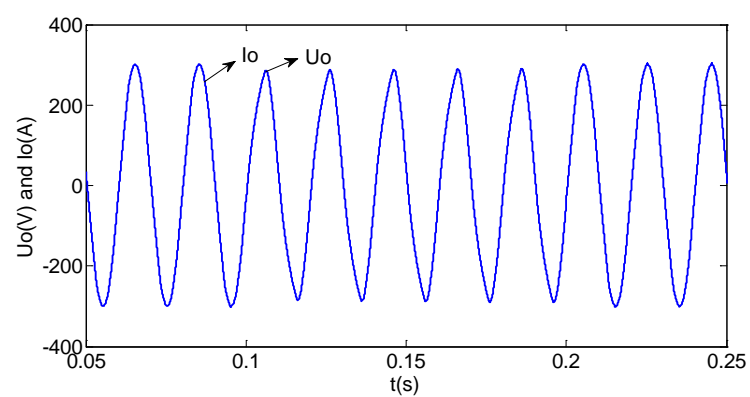

(b)

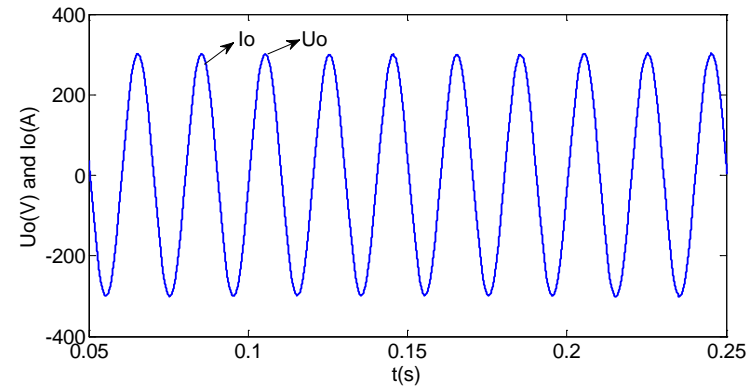

(d)

Figure 7. Simulation results of double power supply with double load. (a) Power voltage, load voltage and compensation voltage waveforms of source $S_{1}$; (b) voltage and current waveforms of source $S_{1}$ in load side; (c) power voltage, load voltage and compensation voltage waveforms of source $\mathrm{S}_{2}$; (d) voltage and current waveforms of source $\mathrm{S}_{2}$ in load side.

Table 2. System parameters of simulation in new compensation scheme.

\begin{tabular}{cc}
\hline Parameters & Value \\
\hline Source voltage $\mathrm{U}_{\mathrm{s}}$ & $220 \mathrm{~V}$ \\
Load R & $1 \Omega$ \\
One-phase load capacity S & $4.84 \mathrm{kVA}$ \\
Transformer ratio K & 1 \\
DC voltage $\mathrm{U}_{\mathrm{dc}}$ & $400 \mathrm{~V}$ \\
Filtering inductance $\mathrm{L}_{\mathrm{f}}$ & $4 \mathrm{mH}$ \\
Filtering capacitor $\mathrm{C}_{\mathrm{f}}$ & $60 \mu \mathrm{F}$ \\
\hline
\end{tabular}

\section{Conclusions}

Through theoretical analysis and simulation studies, we can see that, for various and complex loads in large scale industrial enterprises, the proposed double power supply with double load DVR compensation scheme can well solve the voltage drop problem to guarantee load's normal work. This scheme has no storage energy system, so that it costs less than DVR with energy storage system; has two way supply sources spare to each other, so that it performs better than normal DVR with rectifying system. Therefore, it's a simple and economical scheme and significant for large industrial enterprises to improve power supply reliability and enhance load-side power quality.

\section{References}

[1] Huang, X.-Y. (2011) Dynamic Voltage Restorer Based on Super-Capacitor. M.S. Dissertation, Huazhong University of Science \& Technology, Wuhan.

[2] Love, D.J. (1994) Reliability of Utility Supply Configurations for Industrial Power Systems. IEEE Transaction on In- 
dustry Applications, 30, 1303-1308. http://dx.doi.org/10.1109/28.315243

[3] Han, Y.-D., Jiang, Q.-R., Le, J. and Yan, G.-G. (2003) Modern Electric Power and FACTS\&DFACTS. Electrical Equipment, 4, 5-10.

[4] Nielsen, J.G. and Blaabjerg, F. (2005) A Detailed Comparison of System Topologies for Dynamic Voltage Restorers. IEEE Transactions on Industry Applications, 41, 1272-1280. http://dx.doi.org/10.1109/TIA.2005.855045

[5] Jothibasu, S. and Mishra, M.K. (2014) A Control Scheme for Storageless DVR Based on Characterization of Voltage Sags. IEEE Transactions on Power Delivery, 29, 2261-2269. http://dx.doi.org/10.1109/TPWRD.2014.2316598

[6] Ramachandaramurthy, V.K., Fitzer, C., Arulampalam, A., Zhan, C., Barnes, M. and Jenkins, N. (2002) Control of a Battery Supported Dynamic Voltage Restorer. In IEE Proceedings-Generation, Transmission and Distribution Meeting, Manchester, 533-542.

[7] Liu, X., Zhu, X.-G., Zhu, X. and Jiang, X.-H. (2004) Compensation of Instantaneous Voltage Drop Based on Superconducting Energy Storage. Automation of Electric Power Systems, 28, 40-44.

[8] de Andrade, R., Ferreira, A.C., Sotelo, G.G., Silva Neto, J.L., Rolim, L.G.B., Suemitsu, W.I., Bessa, M.F., Stephan, R.M. and Nicolsky, R. (2005) Voltage Sags Compensation Using a Superconducting Flywheel Energy Storage System. IEEE Transaction on Applied Superconductivity, 15, 2265-2268. http://dx.doi.org/10.1109/TASC.2005.849627

[9] Yang, C., Han, Y.-D., and Ma, W.-X. (2004) Research of Single-phase Series Power Quality Compensator Controller. Automation of Electric Power Systems, 26, 45-48.

[10] Yin, Z.-D. and Zhi, L.-X. (2005) Energy Extraction Method of Dynamic Voltage Restorer Based on High-Frequency Rectifier. Power Electronics, 39, 67-69.

[11] Huang, L. (2012) Research on Voltage Sag Influence the Sensitive Load and Control Measures, M.S. Dissertation, Guangdong University of Technology, Guangzhou.

[12] Guan, X.-B. (2012) Research on Dynamic Voltage Restorer, M.S. Dissertation, Huazhong University of Science \& Technology, Chengdu.

[13] Fu, Y.-S. and Wei, M.-G. (2011) Power Quality Features of Different Industry Loads. Power Capacitor \& Reactive Power Compensation, 32, 11-17.

[14] Sun, W. and Qin, L.-J. (2008) Power Quality Analysis and Control in Iron and Steel Enterprises. Electrical Equipment, 9, 68-71.

[15] Yuan, C. (2005) Research for Real-time Detection of Characteristics of Voltage Sag and Compensation Method of Dynamic Voltage Restorer, M.S. Dissertation, Sichuan University, China.

[16] Wang, B.S. Venkataramanan, G. and Illindala, M. (2006) Operation and Control of a Dynamic Voltage Restorer Using Transformer Coupled H-Bridge Converters. IEEE Transactions on Power Electronics, 21, 1053-1061. http://dx.doi.org/10.1109/TPEL.2006.876836 